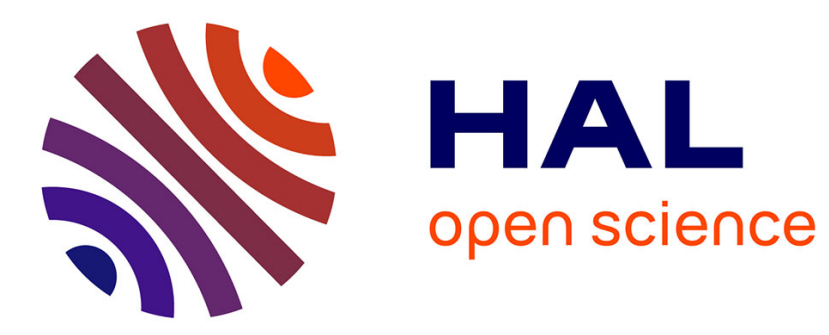

\title{
Multimodal Damping of a Nonlinear Structure with a Passive Piezoelectric Network
}

Boris Lossouarn, Jean-François Deü, Gaëtan Kerschen

\section{To cite this version:}

Boris Lossouarn, Jean-François Deü, Gaëtan Kerschen. Multimodal Damping of a Nonlinear Structure with a Passive Piezoelectric Network. 36th IMAC Conference and Exposition on Structural Dynamics, IMAC XXXVI, Feb 2018, Orlando, United States. pp.161-163, 10.1007/978-3-319-75390-4_15 . hal02171676

\section{HAL Id: hal-02171676 \\ https://hal.science/hal-02171676}

Submitted on 1 Aug 2019

HAL is a multi-disciplinary open access archive for the deposit and dissemination of scientific research documents, whether they are published or not. The documents may come from teaching and research institutions in France or abroad, or from public or private research centers.
L'archive ouverte pluridisciplinaire HAL, est destinée au dépôt et à la diffusion de documents scientifiques de niveau recherche, publiés ou non, émanant des établissements d'enseignement et de recherche français ou étrangers, des laboratoires publics ou privés. 


\title{
Multimodal Damping of a Nonlinear Structure with a Passive Piezoelectric Network
}

\author{
B. Lossouarn, Assistant Professor - J.-F. Deü, Professor \\ Laboratoire de Mécanique des Structures et des Systèmes Couplés, \\ Conservatoire national des arts et métiers, \\ 292 Rue Saint-Martin, 75003 Paris, France \\ G. Kerschen, Professor \\ Department of Aerospace and Mechanical Engineering, University of Liège \\ Allée de la Découverte, 9, B-4000 Liège, Belgium
}

\begin{abstract}
This work proposes the implementation of a multimodal and fully passive piezoelectric tuned vibration absorber that mitigates several resonances of a nonlinear structure. By extending a principle of similarity, an analogous electrical network is designed in order to reproduce the dynamics of the mechanical structure. Several electrical resonances are simultaneously tuned to the mechanical resonances, thus providing the equivalent of a multimodal vibration absorber from electromechanical coupling through an array of piezoelectric patches. Furthermore, the use of a nonlinear capacitor in the analogous network generates an autonomous adjustment of the electrical resonance frequencies when the structure reaches the nonlinear domain. The interest of this method is proved experimentally by mitigating vibration over a wide frequency range that covers the first three modes of a beam with cubic nonlinearity.
\end{abstract}

Keywords: Nonlinear absorber, Multimodal damping, Piezoelectric coupling, Resonant network, Passive control

\section{Introduction}

Considering piezoelectric tuned vibration absorbers, mechanical nonlinearities generate a detuning that seriously affects the damping performance. This limitation of the classical resonant piezoelectric shunt [1] was analyzed by Soltani at al. [2], who extended results obtained by Habib et al. in the case of a purely mechanical absorber [3]. In order to retrieve a correct tuning of the absorber, a solution consists in the introduction of an additional nonlinearity in the electrical circuit. The interest of such a nonlinear piezoelectric shunt has already been proven numericaly and experimentally for vibration mitigation of a single nonlinear resonance [2, 4]. The objective is now to extend the method to multimodal structures by implementing a multi-resonant piezoelectric network [5] that is able to damp several resonances of a nonlinear structure.

\section{Nonlinear piezoelectric tuned vibration absorber}

The experimental setup is based on a cantilever beam involving a cubic nonlinearity. As shown in Fig. 1, a thin lamina is clamped at the left end of the beam, which generates the hardening nonlinearity. The structure is covered with an array of piezoelectric patches in order to mitigate vibration with a piezoelectric tuned vibration absorber [1]. A passive inductor is made by winding copper wire around a magnetic circuit in ferrite material and connected to the piezoelectric patches. A linear inductor allows reducing the vibration amplitude of the beam at low excitation but Fig. 2(a) shows that an increasing forcing amplitude leads to a complete detuning of the resonant shunt because of the mechanical nonlinearity. A solution to overcome this effect is to introduce in the absorber a nonlinearity similar to that of the primary structure [3]. Practically, it can be implemented with a nonlinear capacitor [2] or a nonlinear inductor [4]. Both solutions provide equivalent adaptive tuning by maintaining two equal peaks in the 


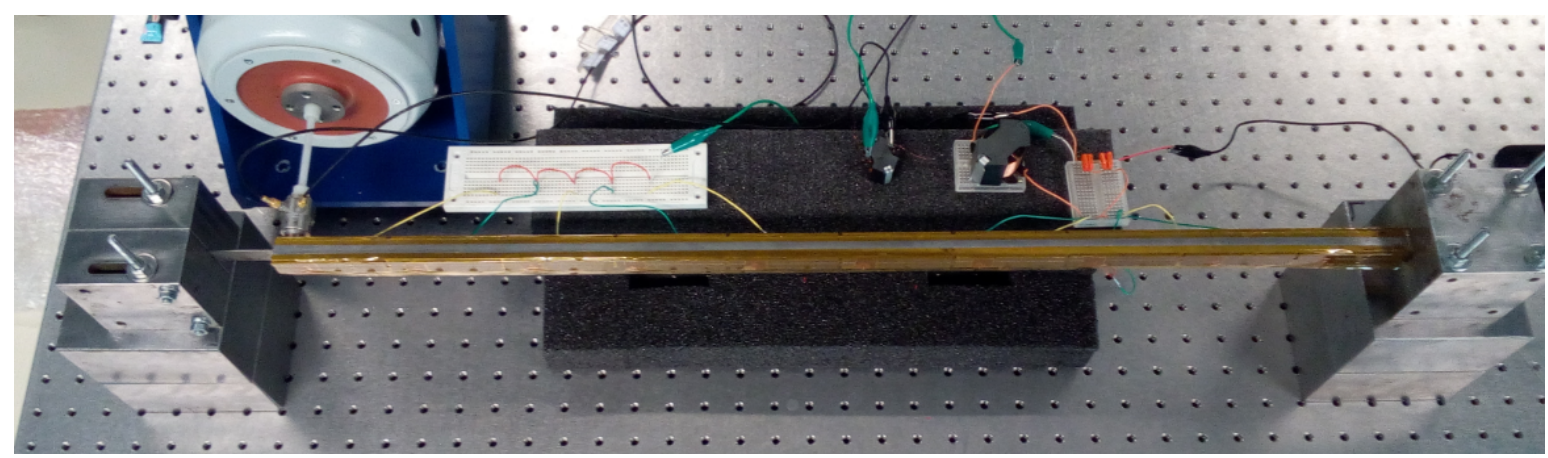

Fig. 1 Cantilever beam with additional clamping through a thin lamina.

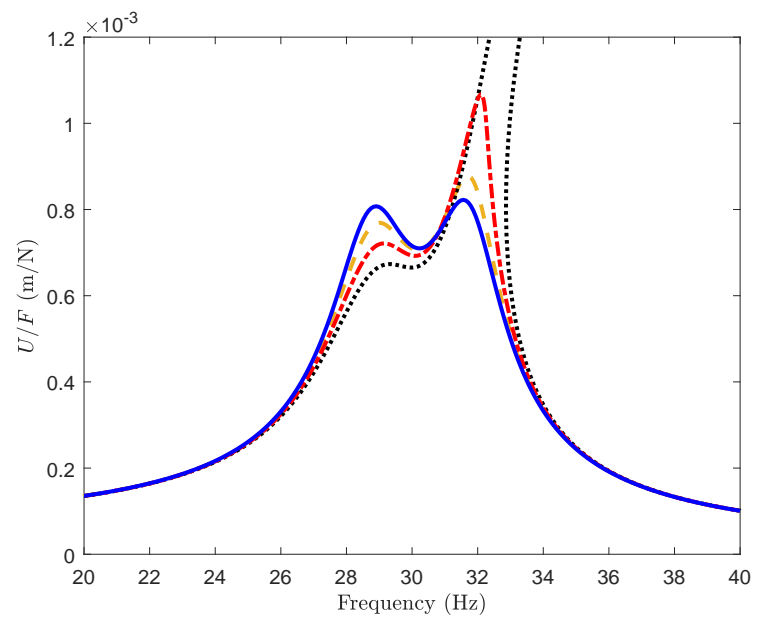

(a)

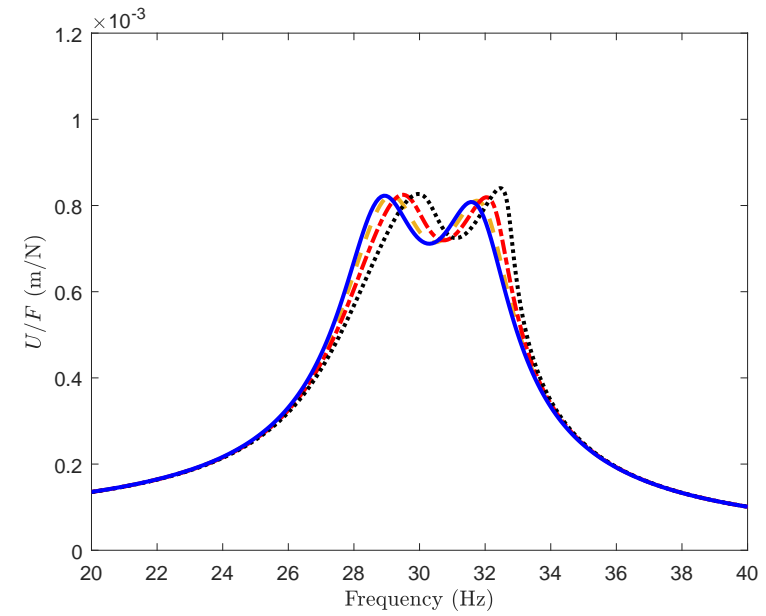

(b)

Fig. 2 Simulated frequency response functions for various forcing amplitudes, $F=0.2 \mathrm{~N}(-), F=0.4 \mathrm{~N}(--)$, $F=0.6 \mathrm{~N}(-\cdot-)$ and $F=0.8 \mathrm{~N}(\cdots)$ : (a) linear shunt, (b) nonlinear piezoelectric tuned vibration absorber.

frequency response function. Such a result represented in Fig. 2(b) has already been proven experimentally by using a physical inductor subjected to magnetic saturation [4].

\section{Multimodal damping with an analogous piezoelectric network}

As the objective of the present work is to achieve vibration damping of several resonances, the array of piezoelectric patches is interconnected with electrical components in order to implement a multi-resonant electrical network. Actually, coupling a mechanical structure to its analogous electrical network generates electromechanical energy transfers over a broad frequency range. The electrical analogue of a beam [5] is considered for the present application. It is a fourth order transmission line made of inductors and transformers, as shown in Fig. 3. Capacitors are not explicitly represented because we directly benefit from the piezoelectric capacitance of the patches that couple the beam to the electrical network. Coupling the mechanical structure to its analogous electrical network gives the frequency response in Fig. 4, which shows the simultaneous vibration mitigation of the first three modes of the beam at low forcing amplitudes. Yet, higher amplitudes still lead to the undesired behavior illustrated in Fig. 2(a) if linear components are used in the electrical network. Contrary to a previous experimental valitation based on a nonlinear inductor [4], a nonlinear capacitor is incorporated in the piezoelectric electrical network to ensure an equivalence with the nonlinear stiffness at the end of the beam. The analogy is not only valid in the linear domain but also in the nonlinear domain thanks to the principle of similarity developed in previous studies on nonlinear vibration absorbers [3, 2]. The damping performance are thus maintained, providing similar frequency response functions for higher forcing amplitudes. 


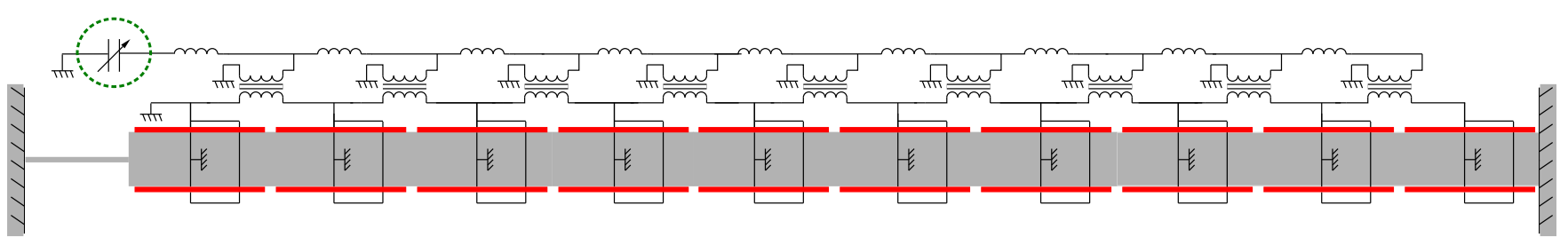

Fig. 3 Nonlinear beam coupled to its analogous electrical network through an array of piezoelectric patches.

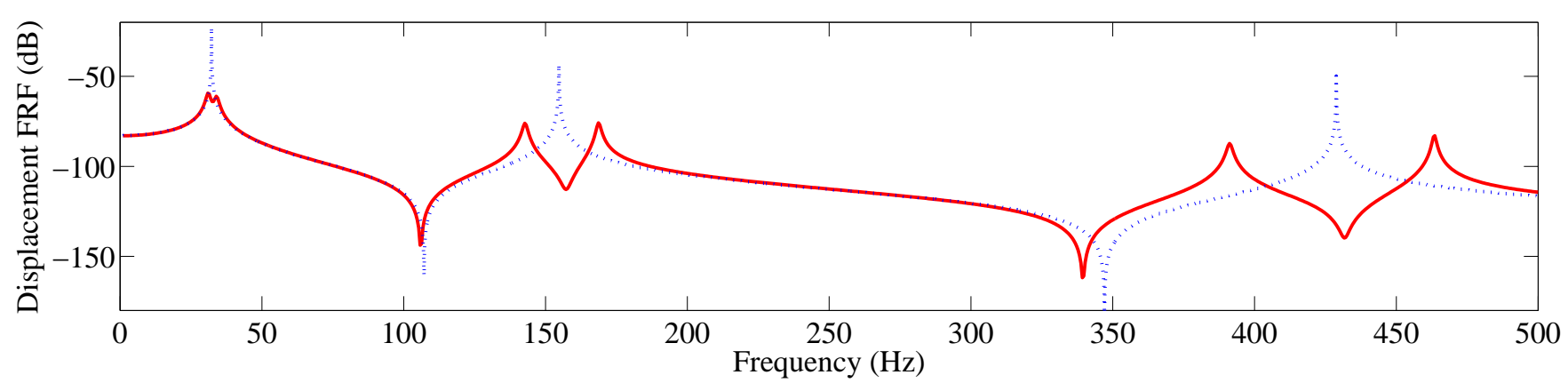

Fig. 4 Simulated frequency response function of the beam with short-circuited patches $(\cdots)$ and with the analogous electrical network (一).

\section{Conclusions}

This work aims to show that the principle of nonlinear similarity can be extended to multimodal damping with piezoelectric networks. To this end, an analogous electrical network is first assembled in order to reproduce the dynamics of the considered structure in the linear domain. A multimodal coupling offers vibration mitigation over a wide frequency range. For higher forcing amplitudes, it is shown experimentally that the mechanical nonlinearity induces a serious mistuning, especially for the first mode of the beam. A nonlinear capacitor is thus used in the electrical network in order to generate variable electrical resonances, which maintain a multimodal vibration reduction. This proves that broadband damping of a nonlinear structure can be achieved with a fully passive vibration absorber.

\section{References}

[1] Hagood, N. W. and von Flotow, A., "Damping of structural vibrations with piezoelectric materials and passive electrical networks," J. Sound Vib., 146:243-268, 1991.

[2] Soltani, P. and Kerschen, G., "The nonlinear piezoelectric tuned vibration absorber," Smart. Mater. Struct. 24:075015, 2015.

[3] Habib, G. and Kerschen, G., "A principle of similarity for nonlinear vibration absorbers," Physica D 332:1-8, 2016.

[4] Lossouarn, B., Deü, J. F. and Kerschen, G., "Passive realization of a nonlinear piezoelectric tuned vibration absorber with a saturable inductor," Proceedings of the 9th European Nonlinear Dynamics Conference, 2017

[5] Lossouarn, B., Deü, J. F. and Aucejo, M., "Multimodal vibration damping of a beam with a periodic array of piezoelectric patches connected to a passive electrical network", Smart Mater. Struct., 24:115037, 2015. 